\title{
Decorative-formative and spatial organization of representative architecture 1930s - early 1950s as a reflection of the state-ideological goal
}

\author{
Liudmyla Bachynska \\ Kyiv National University of Construction and Architecture \\ Povitroflotskyy Avenue 31, Kyiv, Ukraine, 03037 \\ ludmila bachina@ukr.net, orcid.org/0000-0002-6942-5627
}

Received 08.10.2018, accepted for publication 10.09.2018

DOI: 10.26884/uwt1808.1902

It is need to make comparison of the architectural heritage of European countries and the USSR that in the first half of the twentieth century belonged to states with totalitarian political regimes, to establish the main tendencies in their architecture - the common features and differences - and to find out the reasons for their appearance. This time, beginning in the 1920s, marked the emergence of totalitarian regimes in European life as a reaction on the political turmoil that took place in a number of countries after the First World War. The war led to a major political, economic and cultural crisis, in the background of which there was a change of political regimes. A wave of formation of reactionary parties was sweeping through Europe, and Spain, Italy, Portugal and Germany formed a system of government which was based on a one-party system that led by the leader. For these countries it was characterized by rigorous control from the top of power absolutely in all aspects of life - the economy on the basis of private property and market relations, a policy of categorical nonperception of other political forces and movements, culture, which reflected in various forms the idea of creating a social consciousness on the basis of feeling the exclusivity of the nation, and therefore the priority right to resolve the fate of other peoples.
What distinguished the Soviet political system from European political regimes? First, the idea of democracy in the form of local councils of people's deputies (the authorities from below, from the people - upwards) was absorbed by the party system, formed on the principle "on the contrary", as a command system (from the helmsman to the people). Therefore, in the process of perfection, it turned into a conglomerate in which the legislative branch of power became a puppet and completely dependent on the main party component of the system of government $[1,2]$. Second, there was no private property in the USSR. Land and other natural resources, all means of production belonged to the state, were at the disposal and under the strict control of the authorities. Thirdly, public consciousness was formed in the spirit of patriotism, love for national culture, faith in the bright future, which would determine the party leadership (which meant the transfer of responsibility for its own fate to the representatives of the authorities) and friendly relations with other peoples. The public consciousness forming the direction of the development of culture was a consequence of the embodiment of the state-ideological essence of social life to thinking of the society, which was programmed by the leadership of the state. The means of architecture that are under the influence of state ideology, the specifics of the economic system, the formed 
psychology of society and social consciousness, forms an artificial environment of human being, which, on the one hand, reflects socio-political processes, on the other, creates an environment that educates a person in a certain the corresponding direction. Under totalitarian systems, both sides are pushing for a person stronger in the direction desired by the ruling power, limiting its freedom is felt stronger than in a democratic political system.

Consequently, the first half of the twentieth century was marked both in Europe and in the Soviet Union by the creation of totalitarian regimes, which were clearly reflected in the formation of the architectural environment. So whether the common features in the politicaleconomic system, political events and the development of the culture of European states and the USSR influenced onto architecture, its form and style? Have any cardinal differences been observed? When were they, what caused their appearance? Where did the causal link between the political-economic system and architecture look? An overview of the architectural and urban heritage has shown that for all European countries, where reactionary regimes were established, the following was typical: giantomania in the size of objects that were prestigious for the authorities and the state; style building based on national, ancient traditions; purism, asceticism, lapidary and, at the same time, simplicity and monumental forms; axial symmetry of city-building ensembles; moderate, but accurate, in the main places of use of state symbols; application of additional decorative symbols emphasizing the connection with the ancient past: figures of a physically strong man, a bull, horses, more often in the form of sculptures, less often bas-relief; monotonous interpretation of the wall - without cavities or with identical cutouts, which served as a monumental background for a separate sculpture, emphasizing its symbolic meaning. The rationalism of architectural forms was manifested in the purity and concordance of the plan, the architectonics of the building, which brightly and precisely helped to focus the viewer's attention and emphasized the value of a single symbol. The simplicity of the formation of European functionalism, which was combined with the symmetry of the architectural-spatial composition and the neoclassical manifestations of the warrant, the great-power symbols and monumental forms, as well as expensive materials, created a special direction of the open-mindedness of the state-ideological content of architecture. By such means, the architecture articulated outside clearly demonstrative and ideological reference to an absolutely indisputable order in the state, based on conquering the authorities, carrying the order to other peoples and deciding their fate at the discretion of this power.

Before the war, the Soviet Union embarked on a path of rebirth and creative rethinking of the classical heritage. Withdrew from the tendencies of the spread of constructivist industrial forms in the urban environment, Soviet architecture moved through the formation of the Russian empire. Thanks to the desire to glorify the existing system of government at that time, the USSR chose the classic principles in architecture: the classical perimeter building of quarters and the symmetrical structure of the facades were revived; the mandatory formation of the main city center on the basis of the axis of symmetry and the main buildings with towers and spikes in completion, with many state symbols, which looked like an explicit selection of decorative forms and details. In the postwar period, state symbols that had to remind of the role of the Soviet state in the life of the people and to demonstrate the differences between Soviet architecture and the architecture of the Russian Empire, began to appear anywhere. The unlimited number of that symbolism simply shouted about the ideological purpose, but at the same time it reduced its value. In addition to such obsessive use of symbolism, the psychological effect was enhanced by other decorative elements that performed an additional auxiliary function. It is a variety of symbols of fertility, labor, a bright future that awaits the people in the form of justice, equality, peaceful life, and well-being. The combination of a heavy order with a richly decorated facade created in the architecture of a fairy tale about a strong, reliable, mighty state, which promised 
protection and happiness to its people. An unlikely architectural form and style that did not correspond to real situations (repressions in the country and arms race among the states) formed a decorative screen that covered the real state-ideological content of the formed urban environment.

Consequently, the architectural and urban heritage frankly reflected the true manifestations of the state-ideological goal of countries with totalitarian political regimes. The architectural legacy of European states significantly differed from that of the USSR by the fact that European states frankly proclaimed the ambition of their own political programs, and the Soviet state with the help of architectural means created an idyll of peacefulness and a bright future.
Keywords: the architecture, the political regime, the state symbols, the form and style of architecture.

\section{REFERENCES}

1. Bachynska L.G., 2017. Influence of the political regime of the USSR in the 1920 -1940-ies years on the architecture and urban development of Ukraine. Multidisciplinary Scientific Edition Proceedings of the International Scientific Conference Modern Methodology of Science and Education (September 18, 2017, Warsaw, Poland), Vol.01. RS Global, S. z. O.O., Research and Scientific Group, Warsaw, Poland, 15-20.

2. Bachynska Liudmyla, 2017. The development of the architectural object is under the influence of social history. Underwater Technologies, Vol.06, 89-99. 